\title{
The influence of treatment access regulation and technological resources on the mortality profile of acute biliary pancreatitis ${ }^{1}$
}

\author{
A influência da regulação do acesso aos serviços de saúde e da incorporação \\ tecnológica no perfil de mortalidade da pancreatite aguda biliar
}

\author{
Francisco Ribeiro de CarvalhoI, José Sebastião dos Santos ${ }^{\text {II }}$, Jorge Elias Junior ${ }^{\text {III }}$, Rafael Kemp ${ }^{\text {IV }}$, Ajith Kumar \\ Sankarankutty $^{\mathrm{v}}$, Olívia Yumi Fukumori ${ }^{\mathrm{VI}}$, Manoel Carlos L. de Azevedo Souza ${ }^{\mathrm{VII}}$, Orlando de Castro-e-Silva ${ }^{\mathrm{VIII}}$ \\ ${ }^{\text {I }}$ Fellow PhD degree, Division of Digestive Surgery, Department of Surgery and Anatomy, Ribeirão Preto Faculty of Medicine, University \\ of São Paulo, Brazil. \\ ${ }^{\text {II }} \mathrm{PhD}$, Professor, Division of Digestive Surgery, Department of Surgery and Anatomy, Ribeirão Preto Faculty of Medicine, University \\ of São Paulo, Brazil. Brazil.

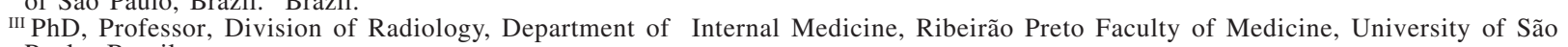 \\ Paulo, Brazil.

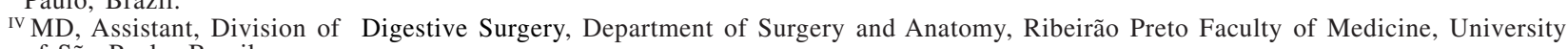 \\ of São Paulo, Brazil. \\ v PhD, Professor, Division of Digestive Surgery, Department of Surgery and Anatomy, Ribeirão Preto Faculty of Medicine, University \\ of São Paulo, Brazil. \\ VI Graduate student of Ribeirão Preto Faculty of Medicine, University of São Paulo, Brazil. \\ VII Graduate student of Ribeirão Preto Faculty of Medicine, University of São Paulo, Brazil. \\ VIII Full Professor and Head Division of Digestive Surgery, Department of Surgery and Anatomy, Ribeirão Preto Faculty of Medicine, \\ University of São Paulo, Brazil.
}

\begin{abstract}
Purpose: The influence of treatment access regulation and technological resources on the mortality profile of acute biliary pancreatitis (ABP) was evaluated. Methods: The cases seen in a tertiary hospital were studied during two periods of time: 1995-1999 and 2000-2004, i.e., before and after the implementation of medical regulation. Results: Among the 727 patients with acute pancreatitis, 267 had ABP and were classified according to APACHE II scores. The cases being referred to the tertiary hospital decreased from 441 to $286(p<0.001)$. The patients' profile regarding age, gender, severity, cholestasis incidence and mortality were similar during the first and second periods of study $(\mathrm{n}=154$ and $\mathrm{n}=113$, respectively). The number of patients with hematocrit $\geq 44 \%$ was smaller during the second study period $(p<0.002)$. The use of magnetic resonance cholangiography, videolaparoscopic cholecystectomy, and access to the ICU were found to be more frequent during the second study period. Regarding the deaths occurring within 14 days of hospitalisation, $73.4 \%$ and $81.3 \%$ were observed during the first and second study periods, respectively. Conclusion: Since the improvement in clinical and technological approach was not enough to modify the mortality profile of ABP, further studies on the treatment of inflammatory responses should be carried out.
\end{abstract}

Key words: Biliary Pancreatitis. APACHE II. Medical Regulation. Cholestasis. Mortality. Emergency.

\section{RESUMO}

Objetivo:Avaliou-se a influência do acesso aos recursos assistenciais e tecnológicos sobre a mortalidade na pancreatite aguda biliar (PAB). Métodos: Os casos de PAB tratados num hospital universitário foram estudados em dois períodos: 1995 a 1999 e 2000 a 2004, antes e depois da implantação da Regulação Médica. Resultados: Do total de 727 casos com pancreatite aguda atendidos, 267 apresentavam PAB e tiveram a gravidade avaliada pelo escore de APACHE II. Houve redução dos encaminhamentos de casos entre os períodos, de 441 para 286 ( $\mathrm{p}<0,001)$. O perfil dos pacientes com PAB no primeiro período $(\mathrm{n}=154)$ e no segundo $(\mathrm{n}=113)$ foi semelhante quanto à idade, sexo, gravidade, incidência de colestase e mortalidade. A incidência de pacientes com hematócrito $\geq 44$ foi menor no segundo período $(p<0,002)$. O emprego de colangiografia por ressonância magnética, da colecistectomia por videolaparoscopia e do acesso à terapia intensiva foi significantemente maior no segundo período. A maioria dos óbitos ocorreu até os 14 dias de admissão, 73,4\% no primeiro período e 81,3\% no segundo. Conclusão:A melhora do suporte tecnológico e clínico não foi suficiente para modificar o perfil de mortalidade na PAB, o que indica a necessidade de avaliar terapêuticas para a sua resposta inflamatória.

Descritores: Pancreatite Biliar. APACHE II. Regulação Médica. Colestase. Mortalidade. Emergência.

1. Work performed in the Division of Digestive Surgery of the Department of Surgery and Anatomy, Ribeirão Preto Faculty of Medicine, University of São Paulo, Brazil. 


\section{Introduction}

In the great majority of cases, severe acute pancreatitis occurs in two phases. During the first couple of weeks, a systemic inflammatory reaction occurs due to the release of various pro-inflammatory cytokines, such as tumour necrosis factor (TNF), interleukins (IL-1, IL-2, IL-6), nitric oxide, oxygen-reactive radicals, and arachidonic acid metabolites. ${ }^{1}$ Two weeks later, pancreatic necrosis and peripancreatic infection with multiple organ failure may occur. $^{2}$.

The overall mortality of acute pancreatitis is $5 \%$ (ranging from 2 to $9 \%$ ), including all other aetiologies. ${ }^{3}$ The mortality occurring during the early phase (two first weeks) ranges from 0 to $82.3 \%{ }^{4,5}$ However, the efforts in identifying mortality determinants in order to develop new therapeutic approaches have not yielded promising results..$^{5-7}$

In the literature there is no study on the mortality profile of acute biliary pancreatitis (ABP) regarding early and late phases, which justifies an evaluation of the possible determinants involved.

In 2000, in an attempt to improve the diagnostic and treatment conditions of acute severe cases seen in the emergency settings, a medical regulation was applied to the ambulance service emergency care (SAMU) which covers the greater Ribeirão Preto. ${ }^{8}$

Medical regulation has the objective of coordinating the available resources according to the health problem involved, so that the best diagnostic and therapeutic alternatives can be provided. Since the implementation of the medical regulation, the Emergency Unit of the Ribeirão Preto University Hospital has been considered a reference point in terms of high complexity cases. As a result, the facilities were architecturally and technologically improved to provide clinical stabilisation and intensive care. ${ }^{8,9}$

Concomitantly, this process of organising the health care system and establishing inpatient references may benefit patients with biliary lithiasis because of the extensive access to videolaparoscopic cholecystectomy. Outpatient care and long-range care have contributed to reducing the waiting list for cholecystectomy among these low-risk surgical patients. ${ }^{10}$ In addition, magnetic resonance cholangiography was gradually implemented as part of examination procedures for biliary duct investigation in the cases of extra-hepatic cholestasis, thus reducing the need for more invasive procedures. ${ }^{11,12}$

Within this context, it is expected that not only the complications resulting from biliary lithiasis will be reduced, particularly acute pancreatitis, but also that the access to emergency units will become more rapid.

The objective of the present study was to evaluate the influence of medical regulation, hospital organisation, and resources for cholelithiasis treatment on the mortality profile of ABP during early and later phases.

\section{Methods}

The medical records of patients over 12 years old who were admitted to the Ribeirão Preto University Hospital or Emergency Unit between January $1^{\text {st }}, 1995$ and December $31^{\text {st }}, 2004$ for ABP treatment were retrospectively reviewed. Information was collected according to the International Disease Code (ICD 9 - 577.0 and ICD 10 - K 85.0).

The study was divided into two periods of time: 1995 to 1999 and 2000 to 2005 . This temporal division was based on the date of implementation of SAMU and medical regulation in the greater Ribeirão Preto area, that is, the periods before and after the year 1999 .

The individual data were gathered according to the medical record review protocol. Epidemiological and clinical information, image and pathological exams, and diagnostic and therapeutic procedures were tabulated on electronic spreadsheets (Microsoft Excel, Seattle, USA).

ABP diagnosis was based on the presence of at least two or three criteria: 1) upper abdominal pain, 2) serum levels of amylase and/or lipase $\geq 3$ times their normal values; 3) computed tomography (CT) or magnetic resonance (MR) findings commonly observed in acute pancreatitis. ${ }^{3}$ The presence of biliary lithiasis was diagnosed using abdominal CT, MR or ultrasonography. ABP severity was evaluated according to both APACHE II score ${ }^{13}$ and Atlanta classification. ${ }^{14}$ Data for the first 24 hours of hospitalisation were collected for evaluation using APACHE II score. If this information was not available, a corresponding normal value was used instead.

Mortality was considered precocious if death occurred within 14 days following admission. The APACHE II score was calculated using an electronic plan available at www.sfar.org/scores2.

The differences between the mean APACHE II values and the percent death risk were determined by the Student " $t$ " test, the frequencies were evaluated by the Fisher exact test and the Pearson Chi-square test, and the medians were evaluated by the Mann-Whitney test.

The values obtained were expressed as mean and standard deviation, with the level of significance set at $\alpha=$ $0.05(\mathrm{P} \leq 0.05)$. The frequencies were expressed as percent values. Bonferroni correction was applied to multiple intraperiod comparisons. A receiver operating characteristic (ROC) curve was constructed to validate the APACHE I score.

\section{Results}

A total of 727 cases of acute pancreatitis were diagnosed over the 10-year evaluation period, 441 (60.7\%) being treated between 1995-1999 and $286(39.3 \%)$ between 2000-2004. A significant decrease $(p<0.001)$ in the emergency referrals was found, mainly regarding cases of alcohol-related acute pancreatitis (Figure 1). 
1).

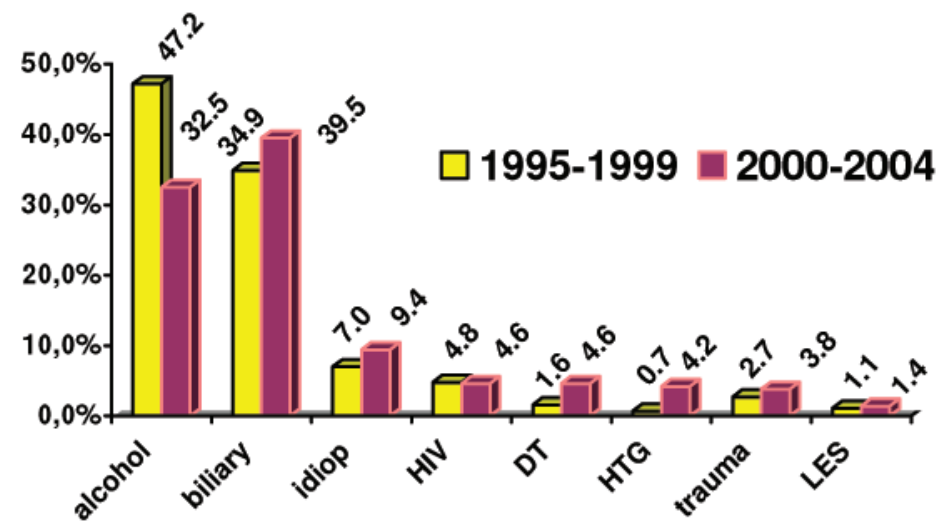

FIGURE 1 - Distribution of cases of acute pancreatitis based on aetiological findings during the 1995-1999 and 20002004 study periods . Idiop = idiopathic; DT = drug therapy; HTG = hypertriglyceridemia; $\mathrm{SLE}=$ systemic lumps erythematosus.

Of all cases evaluated, 267 had biliary involvement (36.7\%), 154 being treated during the first study period (34.9\%) and 113 during the second (39.5\%).

No significant differences were found between groups regarding gender $(p=0.887)$, age $(p=0.959)$, severity ( $p=0.873)$, APACHE II score $(p=0.224)$, cholestasis incidence $(p=0.504)$, length of hospitalisation $(p=0.630)$, and progress to death or survival $(p=0.268)$. Nevertheless, the prevalence of patients with hematocrit $\geq 44 \%$ was found to be significantly lower during the second study period ( $p$ $<0.002$ ).

With respect to the image exams used to diagnose biliary involvement in the cases of acute pancreatitis, a significant increase was observed in magnetic resonance cholangiography. Among the therapeutic procedures, videolaparoscopic cholecystectomy was increasingly used while both open cholecystectomy and endoscopic retrograde cholangiopancreatography were decreasingly used following a 72-hour period (Table 1).

TABLE 1 - Distribution of the diagnostic and therapeutic procedures to which patients with ABP were submitted during the 1995-1999 and 2000-2004 periods.

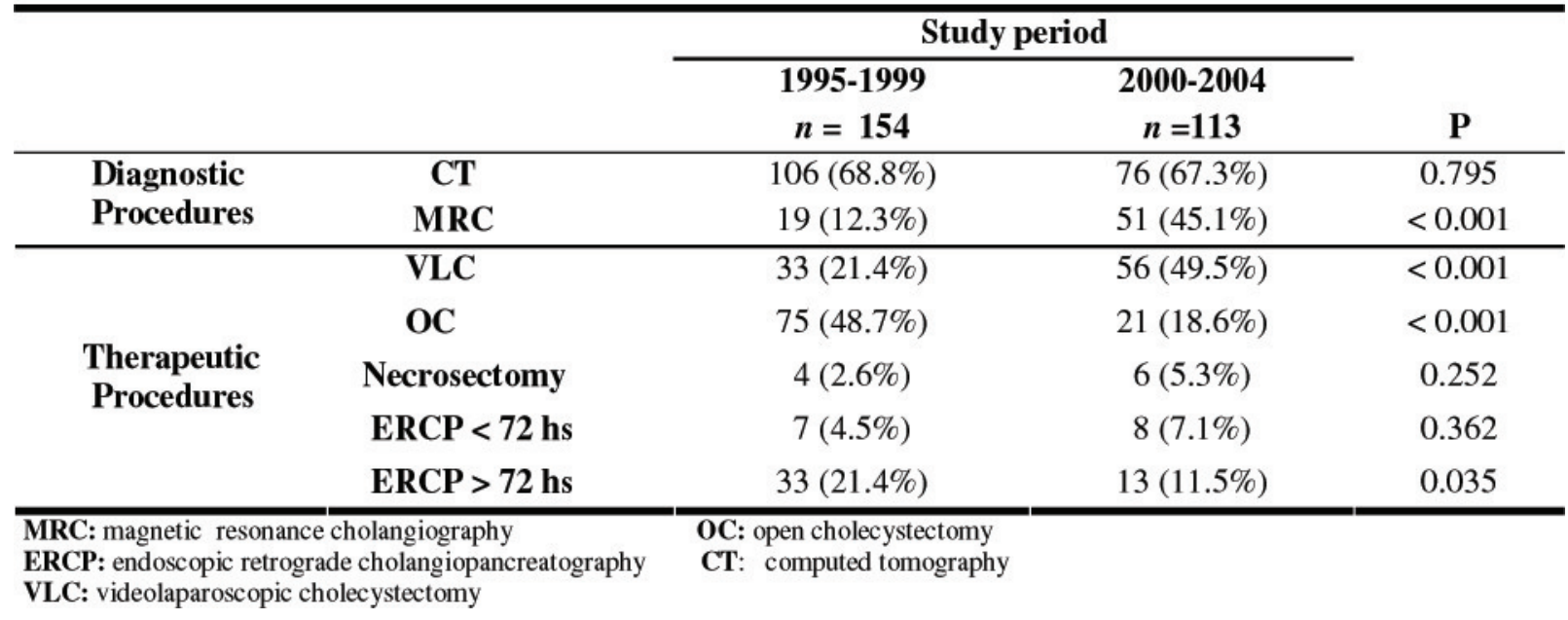


Cholestasis was observed in almost $60 \%$ of the patients during both study periods. Investigation by means of MRC was significantly more frequent during the second study period, whereas a non-significant decrease in the use of ERCP and intra-operative cholangiography was observed. The incidence of choledocholithiasis was low during both study periods, with no significant difference between them (Table 2).

TABLE 2 - Evaluation of the incidence of cholestasis based on the image exams used to investigate the main biliary duct in patients with ABP (1995-1999 and 2000-2004 periods).

\begin{tabular}{cccc}
\hline & \multicolumn{2}{c}{ Study period } & \\
\cline { 2 - 3 } & $\mathbf{1 9 9 5 - 1 9 9 9}$ & $\mathbf{2 0 0 0 - 2 0 0 4}$ & $\mathbf{P}$ \\
\hline Cholestasis Exams & $\boldsymbol{n}=154$ & $\boldsymbol{n}=113$ & 0.504 \\
- MRC & $85(55.2 \%)$ & $67(59.3 \%)$ & $<0.001$ \\
- IOP & $10(11.7 \%)$ & $39(58.2 \%)$ & 0.087 \\
- ERCP & $27(31.7 \%)$ & $13(19.4 \%)$ & 0.382 \\
Exams with calculus & $31(36.5 \%)$ & $18(26.9 \%)$ & 0.911 \\
\hline MRC: magnetic resonance cholangiography & $23(33.8 \%)$ & $23(32.8 \%)$ & \\
ERCP: endoscopic retrograde cholangiopancreatography & IOP: intra-operative cholangiography &
\end{tabular}

The use of intensive care for patients with severe ABP increased significantly during the second study period, although only $40 \%$ of the cases had been successful. Despite being statistically equivalent, the estimated 3-day period on a waiting list was found to be long, even during the second study period (Table 3).

TABLE 3 - Use of intensive care by patients with severe ABP during the 1995-1999 and 2000-2004 periods.

\begin{tabular}{lccc}
\hline & \multicolumn{3}{c}{ Study period } \\
\cline { 2 - 4 } & $\mathbf{1 9 9 5 - 1 9 9 9}$ & $\mathbf{2 0 0 0 - 2 0 0 4}$ & $\mathbf{P}$ \\
\hline Intensive Care & $\boldsymbol{n}=49$ & $\boldsymbol{n}=37$ & 0.036 \\
Length of ICU stay (days) & $7(14.3 \%)$ & $5.2 \pm 4.8$ & 0.268 \\
Time elapsed before intensive care & $7.8 \pm 5.6$ & $3.2 \pm 4.9$ & 0.694 \\
Total length of hospital stay (days) & $2.4 \pm 2.9$ & $13.6 \pm 15$ & 0.525 \\
\hline
\end{tabular}

The overall mortality rate for $\mathrm{ABP}$ cases was $11.6 \%$. Mild ABP (APACHE II < 8) accounted for $68.2 \%$ (mortality rate of $3.8 \%$ ) and $67.3 \%$ (mortality rate of $3.9 \%$ ) of all cases, respectively, during the first and second study periods. In contrast, severe $\mathrm{ABP}$ represented $31.8 \%$ (mortality rate of $22.4 \%$ ) and $32.7 \%$ (mortality rate of $35.1 \%$ ) of all cases, respectively, during the first and second study periods. No significant difference was found between study periods (Figure 2). 
$\mathbf{n}$

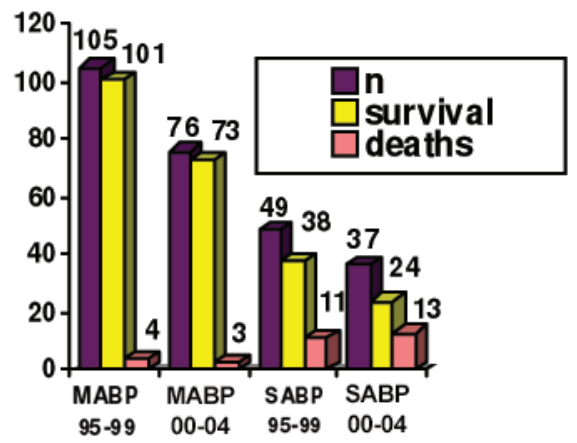

MABP $=$ mild acute biliary pancreatitis $1995-1999 / 2000-2004$

SABP = severe acute biliary pancreatitis $1995-1999 / 2000-2004$

FIGURE 2 - Distribution of patients with $\mathrm{ABP}$ in relation to survival and deaths according to APACHE II scores (mild $<8$ and severe $\geq 8$ ) during the 19951999 and 2000-2004 periods.

Approximately $70 \%$ of the deaths occurred within two weeks after the onset of the disease. During this first phase, $69.5 \%$ of the deaths were related to the systemic inflammatory response syndrome (SIRS), whereas sepsis was predominant $(87.5 \%)$ during the second phase (Table 4).

TABLE 4 - Distribution of patients with ABP treated during the 1995-1999 and 2000-2005 periods according to phase during which death occurred and respective APACHE II score.

\begin{tabular}{|c|c|c|c|}
\hline \multirow[b]{2}{*}{ Deaths (mean) } & \multicolumn{2}{|c|}{ Study period } & \multirow[b]{2}{*}{$\mathbf{P}$} \\
\hline & 1995-1999 & 2000-2004 & \\
\hline Up to 14 days $-n$ & $1(73.4 \%)$ & $13(81.3 \%)$ & \\
\hline After 14 days - n & $4(26.6 \%)$ & $3(18.7 \%)$ & 0.685 \\
\hline $\mathbf{p} *$ & $0.12^{*}$ & $0.021 *$ & \\
\hline APACHE II (median) & 1995-1999 & $2000-2004$ & $\mathbf{P}$ \\
\hline Up to 14 days & $11.0(10)^{* *}$ & $15.0(7.5)^{* *}$ & 0.467 \\
\hline After 14 days & $8.5(12.3)^{* *}$ & $6.0(8.0)^{* *}$ & 0.999 \\
\hline $\mathbf{p}$ & 0.359 & 0.138 & \\
\hline
\end{tabular}

A ROC curve was drawn for the APACHE II score. The sensitivity $(74.2 \%)$ and specificity $(81.2 \%)$ for the prediction of death were based on the APACHE II score $(\geq$ 8.5) (Figure 3). 


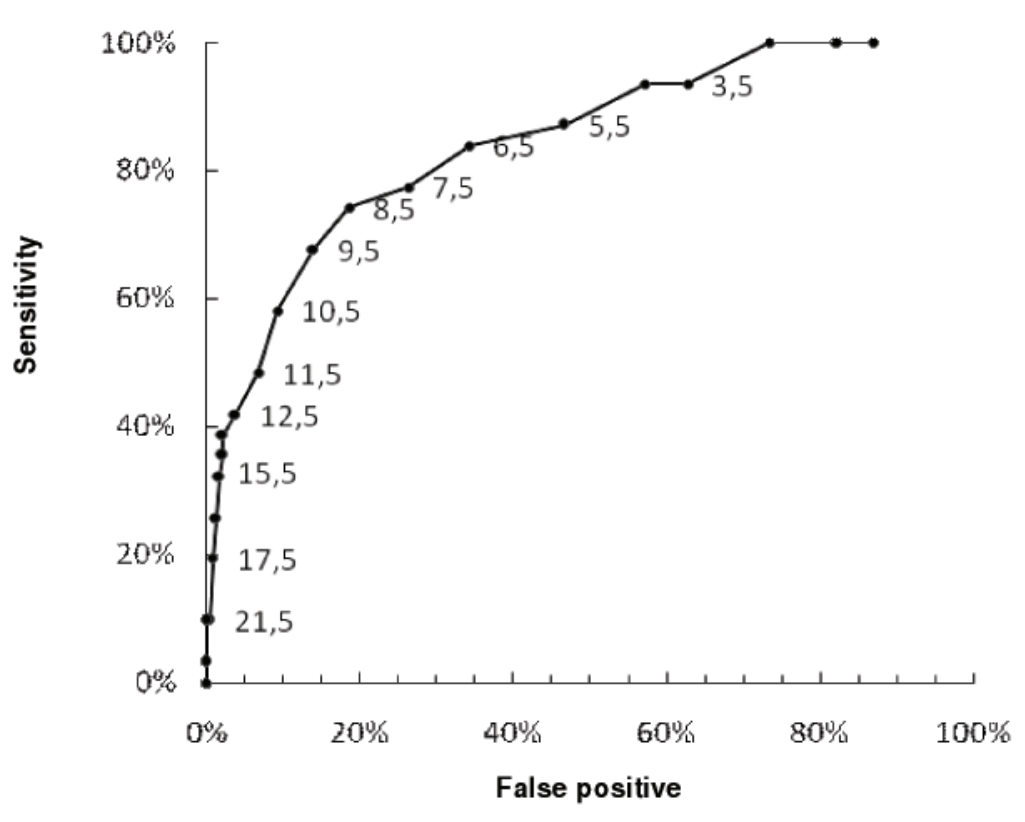

FIGURE 3 - ROC curve for APACHE II scores.

\section{Discussion}

The evaluation of the influence of organization of the health system, of hospital service and of its technological incorporation into the profile of severity and the mortality rate in ABP is a novelty. When the present study was formulated the expectation was that the incidence of ABP cases would be reduced among patients of good anaesthetic and surgical risk as a function of the expanded access to the treatment of colelithiasis by videolaparoscopy on an ambulatory basis and eventually due to the increased frequency of more serious cases at the reference hospital because of the application of medical regulation ${ }^{8,9,10}$.

The objective of this two-phased study was to determine the impact of a more extensive access to the treatment of symptomatic cholelithiasis on the mortality profile and rates of ABP. This includes videolaparoscopic cholecystectomy and non-invasive evaluation of the biliary ducts by means of MRC. By comparing the two study periods, it can be seen that the number of cholecystectomies was increased in the Ribeirão Preto region. Based on the information obtained from the Data Processing Centre of the Department of Social Medicine, School of Medicine of Ribeirão Preto, University of São Paulo, cholecystectomy was performed 12,936 times between 1995 and 1999 and 15,327 times between 2000 and 2004, an increase of $18.5 \%$. The access to videolaparoscopic cholecystectomy increased from $29 \%$ to $64 \%$ at the Ribeirão Preto University Hospital.

The access to health care services by means of medical regulation has significantly improved the working conditions as well as the emergency care unit. Between the years of 1999 and 2000, a significant reduction in the number of consultations was observed, from 114,311 to 56,752. Also, the number of inpatient beds decreased from 113.3 to $97.1 \%$. Concomitantly, the hospital wards were redefined and the number of beds for critical patients was increased from 16 (7.1\%) to $43(21 \%)$ units compared to the total inpatient beds. ${ }^{8,9}$

Within this changing scenario, an overall reduction of $35.1 \%$ was observed in all cases of acute pancreatitis referred to the emergency care unit after implementation of both medical regulation and SAMU, despite the fact that the general population increased by $11.5 \%$ during the study period. In addition, alcohol-related acute pancreatitis and biliary pancreatitis respectively decreased by $55.3 \%$ and $26.6 \%$. However, ABP was found to be slightly increased (4.6\%) during the 2000-2004 study period.

Because of the decreased number of patients, the more severe cases of ABP were expected to be referred to the emergency care unit. However, this fact was not observed. Not only the proportion of cases of mild ABP seen during both the first and second periods of study, but also the disease profile regarding age, gender, cholestasis incidence, severity, APACHE II score, and mortality were the same. However, a lower number of patients with haemoconcentration $(P<0.002)$ was seen in the second study period, thus indicating improvement in the clinical care services.

Even though clinical care was improved and access to MRC, VLC, and intensive care was significantly extended, the mortality profile of ABP was not sufficiently modified in the second-period cases despite the resources available.

During both study periods, the overall mortality rate for $\mathrm{ABP}$ was $11.6 \%$, which is slightly higher than the 
maximum value reported in the literature on acute pancreatitis (ranging from $2 \%$ to $9 \%$ ). ${ }^{3}$

No difference in the mortality rate of patients with mild ABP was found between the two study periods, a finding also observed in severe ABP. The overall mortality rate for patients with mild $\mathrm{ABP}$ was $3.8 \%$, similar to that reported elsewhere $(3.0 \%$, ranging from $1 \%$ to $7 \%) .^{3}$ In the present study, the overall mortality rate for severe ABP was $27.9 \%$, which corresponds to the limits found in the literature (17\%, ranging from $8 \%$ to $39 \%){ }^{3}$ However, significant differences in age and APACHE II score were found between patients who survived and those who died, a finding already observed in other study on pancreatitis of various aetiologies. ${ }^{2}$

The determinants of high mortality during the early phase of ABP are not known. Clinical stabilisation can be an important factor to avoid multiple organ failure (MOF), thus reducing the mortality rate. ${ }^{5}$ Another factor playing a relevant role in $\mathrm{ABP}$ evolution is the time elapsed between onset of the symptoms and hospitalisation, including the intensive care. ${ }^{2}$ Although the access to intensive care was found to be extensive during the second study period, the time elapsed between admission to the hospital and referral to intensive care did not change, with the first 72 hours remaining uncovered and corresponding to the period during which $33.3 \%$ and $50.0 \%$ of the deaths were concentrated in the first and second phase of the study, respectively. Of the patients who died, $70 \%$ were males over 70 years old (mean age: $74+10.4$ years).

There is a great discrepancy between the mortality and morbidity profiles of acute severe pancreatitis. Mortality in the early phase ranged from 0 to more than $80.0 \% .^{2,45} \mathrm{It}$ seems that precocious organ failure is determined by the extent to which necrosis affects the pancreatic parenchyma. In addition, organ failure diagnosed at admission increases the risk of MOF since $80 \%$ of the patients with acute severe pancreatitis characterised within 72 hours end up developing MOF despite the intensive care they receive. It should be noted that the progression of organ failure resulting from the disease itself during the first week of hospitalisation is associated with an increased mortality rate. $^{7}$

In the present study, most deaths occurred during the first two weeks, the main cause being the systemic inflammatory response syndrome $(69.5 \%)$. After this $14-$ day period, the main cause of death was sepsis $(87.5 \%)$. The main therapeutic problem regarding severe acute pancreatitis is the clinical intensive care for organ failure recovery. ${ }^{4}$ Despite the statement that deaths occurring in the early phase of ABP have been a rare event since the improvements in the intensive care unit, several studies have shown that many patients die during the first couple of weeks following hospitalisation. ${ }^{6}$ Patients with acute pancreatitis and MOF complication represent a clinical challenge in view of the lack of a specific therapy. It was shown that surgical intervention earlier than 2 weeks after the onset of symptoms is associated with a prohibitive mortality rate. Late interventions should be limited to those patients with necrosis infection, although the mortality rate remains elevated in the MOF cases regardless of the kind of surgical intervention. ${ }^{6}$ On the other hand, recent efforts have been made to improve the results using minimally invasive procedures or percutaneous drainage and antibiotics. ${ }^{14}$

The APACHE II score has been used during hospitalisation in order to predict the possibility of death based on the ROC curve. A sensitivity of $74.2 \%$ and specificity of $81.4 \%$ for APACHE score $\geq 8.5$ were obtained in the present study, which were higher than those found elsewhere, i.e., sensitivity ranging from $68 \%$ to $71 \%$ and specificity ranging from $48 \%$ to $67 \%$ for APACHE II score $\geq$ 8 during hospitalisation. ${ }^{15}$

Therefore, in spite of the fact that both medical regulation and SAMU have reduced the number of patients being admitted to emergency care units, and despite the technological and therapeutic resources, the mortality and severity rates for $\mathrm{ABP}$ cases have not been sufficiently reduced. Early identification of severe cases and immediate referral to an intensive care unit can open a new perspective in the evaluation of other therapeutic modalities for treating the acute inflammatory reaction, which probably will improve the prognosis for patients with ABP.

\section{References}

1. Makhija R, Kingsnorth A. Cytokine Storm in Acute Pancreatitis. J Hepatobiliary Pancreat Surg. 2002;9:401-10.

2. Gloor B, Muller CA, Worni M, Martignoni ME, Uhl W, Buchler MW. Late Mortality in Patients with Severe Acute Pancreatitis. Br J Surg. 2001;88:975-9.

3. Banks PA, Freeman ML; Practice Parameters Committee of the American College of Gastroenterology. Practice Guidelines in acute pancreatitis. Am J Gastroenterol. 2006; 101:2379400.

4. Carnovale A, Rabitti PG, Manes G, Esposito P, Pacelli L, Uomo G. Mortality in Acute Pancreatitis: Is It an Early or late Event? JOP. 2005;6:438-44.

5. Fu CY, Yeh CN Hsu JT, Jan YY, Hwang TL. Timing of Mortality in Severe Acute Pancreatitis: Experience from 643 Patients. World J Gastroenterol. 2007;13:1966-9.

6. Mckay CJ, Imrie CW. The Continuing Challenge of Early Mortality in Acute Pancreatitis. Br J Surg. 2004;91:1243-4

7. Isenmann R, Rau B, Beger HG. Early Severe Acute Pancreatitis: Characteristics of a New Subgroup. Pancreas. 2001;22:274-8.

8. Santos JS, Scarpelini S, Brasileiro SLL, Ferraz CA, Dallora MELV, Sá MFS. Avaliação do Modelo de Organização da Unidade de Emergência do HCFMRP-USP, adotando, como referência, as Políticas Nacionais de Atenção às Urgências e de Humanização. Medicina. 2003;36:498-515.

9. Santos JS. Da Fundação e Hospital das Clínicas à Criação da Unidade de Emergência e sua Transformação em Modelo Nacional de Atenção as Urgências. Medicina. 2002;35:403-18. 
10. Santos JS, Elias Jr. J, Santos RSF, Módena, JLP, Ceneviva, R. Colangiografia por Ressonância Magnética na Avaliação da Obstrução Biliar Extra-Hepática. Acta Cir Bras. 1997;12( Supl I):27-9.

11. Makary MA, Duncan MD, Harmon JW, Freeswick PD, Bender JS, Bohlman M, Magnuson TH. The Role of Magnetic Resonance Cholangiography in the Management of Patients with Gallstone Pancreatitis. Ann Surg. 2005;241:119-24.

12. Knaus WA, Draper EA, Wagner DP, Zimmerman JE. Apache II: Severity of Disease Classification. Crit Care Med. 1985;13:818-29.
13. Bradley El 3rd. A Clinically based Classification System for Acute Pancreatitis. Arch Surg. 1993;128:586-90.

14. Lee KJ, Kwak KK, Park JK, Yoon WJ, Lee SH, Ryu KK, Kim YT Yong YB. The Efficacy of Nonsurgical Treatment of Infected Pancreatic Necrosis. Pancreas. 2007;34:399-404.

15. Whitcomb DC. Acute Pancreatitis. N Engl J Med. 2006;354:2142-50.

\section{Correspondence:}

Francisco Ribeiro de Carvalho Neto

Av Brigadeiro Faria Lima, 5416

15090-000 - São José do Rio Preto, SP, Brazil

No conflict of interest

Phone: 55(17)32015000

Financial support: FAEPA

frcneto@terra.com.br

\section{How to cite the article:}

Carvalho Neto FR, Fukumori OY, Souza MCLA, Elias Jr J, Sankarankutty AK, Santos JS, Castro-e-Silva O. The influence of treatment access regulation and technological resources on the mortality profile of acute biliary pancreatitis. Acta Cir Bras [serial on the Internet], 2008; 23 Suppl 1. Available from URL: http://www.scielo.br/acb.

\section{Comments:}

A landmark is established by this study on surgical affections and their relations to the quality of medical attention, equally through mechanisms of medical regulation or evaluation and treatment with more modern resources. The introduction is succinct, well characterized and objective as are the aims of the study. Patients and methods are adequately described. The results are unambiguous and the statistics seem appropriate. The discussion addresses all the points raised by the results. In summary, this study certainly will contribute to the knowledge on biliary pancreatitis in this country.

\section{Luis Donizeti Silva Stracieri}

MD, PhD, Department of Surgery and Anatomy, Ribeirão Preto Faculty of Medicine, University of São Paulo, Brazil. 